\title{
Functional Analysis of the TAN-I Gene, a Human Homolog of Drosophila Notch
}

\author{
J. Aster, ${ }^{*}$ W. Pear, $\ddagger$ R. Hasserjian, ${ }^{*}$ H. Erba,${ }^{*} \dagger$ F. Davi, ${ }^{*}$ \\ B. LUo, * M. ScotT $\ddagger$ D. Baltimore, $\ddagger$ AND J. SkLaR* \\ *Division of Molecular Oncology, Department of Pathology, and †Division of Hematology-Oncology, \\ Brigham and Women's Hospital, Harvard Medical School, Boston, Massachusetts 02115; \\ $\ddagger$ Department of Biology, Massachusetts Institute of Technology, Cambridge, Massachusetts 02142
}

The $T A N-1$ gene was originally discovered at the breakpoint of a recurrent $(7 ; 9)(\mathrm{q} 34 ; \mathrm{q} 34.3)$ chromosomal translocation found in a subset of human T-lymphoblastic leukemias (Reynolds et al. 1987; Smith et al. 1988; Ellisen et al. 1991). This translocation joins roughly the $3^{\prime}$ half of $T A N-1$ head-to-head with the $3^{\prime}$ portion of the $\beta$ T-cell-receptor gene $(T C R B)$ beginning at the $5^{\prime}$ boundary of one or the other J segment. Intact $T A N-1$ is normally transcribed into an $8.2-\mathrm{kb}$ transcript that is present in many tissues, most abundantly in developing thymus and spleen (Ellisen et al. 1991). This tissue distribution and the apparent involvement of an altered version of the gene in T-cell cancers have suggested that $T A N-1$ normally has some special function in lymphocytes or their precursors.

Nucleotide sequence analysis of the $T A N-1$ transcript has revealed a single open reading frame of 2555 codons. The predicted amino acid sequence is highly homologous to the product of the Drosophila gene Notch. This gene encodes a transmembrane protein that has been implicated in cell fate decisions between alternative differentiative pathways in a variety of tissues during both embryonic and adult fly development. Most data suggest that the protein product of Notch functions as a receptor in a signaling pathway (Fortini and Artavanis-Tsakonis 1993; Ghysen et al. 1993). The similarity of the TAN-1 and Notch proteins (referred to here as tan-1 and notch) includes a series of shared sequence motifs within the primary structures of the two proteins (summarized in Fig. 1). Other Notch homologs have been identified recently in mice (Franco del Amo et al. 1992; Reaume et al. 1992; Lardelli and Lendahl 1993), rats (Weinmaster et al. 1991, 1992), zebrafish (Bierkamp and Campos-Ortega 1993), and Xenopus (Coffman et al. 1990). In mice, there are at least three closely related homologs, Notch1-3, in addition to one more distantly related homolog, Int-3, which shares most structural motifs with the other genes (Robbins et al. 1992). A partial sequence of human Notch2, termed $h N$ (Stifani et al. 1992), has also been reported, indicating the existence of a Notch gene family in humans as well as mice.

We decided to investigate the $T A N-1$ gene and its role in oncogenesis for a number of reasons. First, homology between genes at chromosomal breakpoints in human cancers and developmental genes from Dro- sophila has become a common theme in molecular oncology. $T A N-1$ was among the first such genes identified, and we were interested in the interrelationship between tumor formation and normal differentiation. We were also curious about the significance of alterations in $T A N-1$ with respect to malignant transformation. The karyotypes of neoplasms with the $t(7 ; 9)(q 34 ; q 34.3)$ contain few other cytogenetic abnormalities. Nevertheless, it is always possible that certain obscure mutations play a more fundamental role in transformation and that translocations involving $T A N$ 1 merely provide some marginal proliferative or surviv-
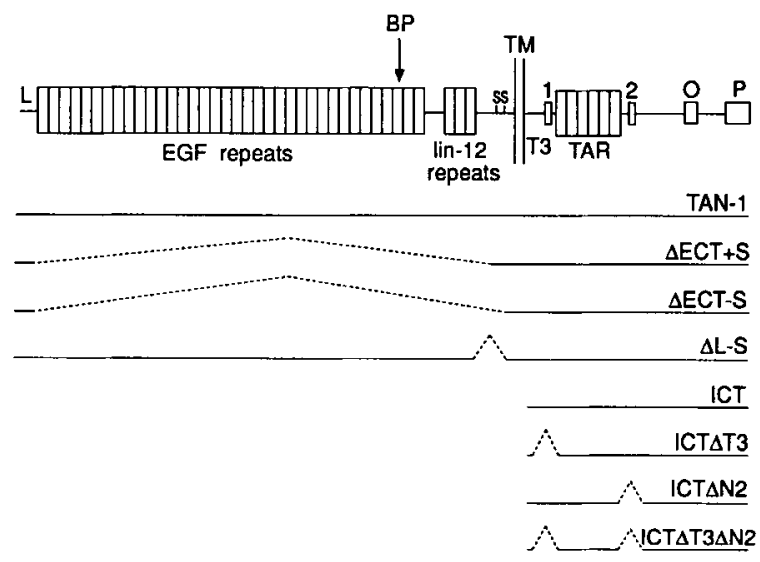

Figure 1. Schematic representation of the tan-1 protein and polypeptides expected to be expressed from various cDNA constructs. The positions of structural motifs within the fulllength protein based on the cDNA sequence are shown at the top. (L) Leader sequence; (EGF repeats) epidermal growth factor-like repeated sequences; (BP) position at which the amino acid sequence of $\tan -1$ would be disrupted by the breakpoints in the $t(7 ; 9)(q 34 ; q 34.3)$ in all such translocations analyzed to date; (lin-12 repeats) repeated sequences resembling those found in the Lin-12 gene of C. elegans; (SS) highly conserved cysteines found in all Notch-related genes and located 49 and 42 amino acids external to the transmembrane domain in tan-1; (TM) transmembrane domain; (1 and 2) two putative nuclear localization signals; (T3) region between the transmembrane domain and the ankyrin repeats used as an immunogen; (TAR) ankyrin-like repeats; (O) glutamine and proline-rich region resembling an opa sequence; $(\mathrm{P})$ region containing proline, glutamate, serine, and threonine, which resembles a PEST sequence. Portions of the full-length tan-1 protein expected to be expressed by the cDNA constructs are shown as solid lines at the bottom; interstitial deleted segments are indicated by dashed lines. 
al advantage to cells that had already undergone transformation due to the effects of these other mutations. Additionally, the fact that only a fraction (perhaps 3 $5 \%$ ) of T-lymphoblastic neoplasms contain the $\mathrm{t}(7 ; 9)(\mathrm{q} 34 ; \mathrm{q} 34.3)$ and that these neoplasms are not readily distinguishable from other T-lymphoblastic tumors by any outstanding morphological, histochemical, or immunologic feature also suggests that alterations in $T A N-1$ may constitute only a secondary phenomenon which follows the primary transformation event. Finally, we believed that insights into the function of any of the several structural motifs within tan-1 might provide clues to the role of similar regions in the relatively large number of proteins that share these motifs. With these considerations in mind, we have proceeded in analysis of the $T A N-1$ gene along five different lines of investigation: (1) structural characterization of tan-1 in cells with and without the $t(7 ; 9)(\mathrm{q} 34 ; \mathrm{q} 34.3) ;(2)$ analysis of the subcellular location of $\tan -1 ;(3)$ in vivo transformation of murine bone marrow stem cells by $T A N-1$ cDNA; (4) identification of an intracellular ligand of tan-1; and (5) detection of a possible role for tan-1 in transcriptional activation.

\section{EXPERIMENTAL PROCEDURES}

Materials. Enzymes used in cloning procedures were obtained from New England Biolabs. Unless otherwise indicated, cell culture reagents were obtained from Gibco-BRL.

Cells and cell lines. The cell lines SUP-T1 and Jurkat were grown in RPMI 1640 supplemented with $10 \%$ heat-inactivated fetal calf serum. 293T cells were grown in Dulbecco's modified Eagle's medium supplemented with $10 \%$ heat-inactivated calf serum; NIH3T3 cells were grown in the same medium supplemented with $10 \%$ donor calf serum.

Synthesis of cDNA expression constructs. TAN-1 constructs were assembled from previously described cDNAs (Ellisen et al. 1991) using standard cloning methods. DNA sequences encoding various portions of the protein (Fig. 1), including the $T A N-1$ translational start site and $5^{\prime}$ signal peptide, the $\mathrm{T} 3$ region, and the TAR region, were amplified from cDNA templates by PCR. The cDNA expression constructs assembled from these PCR products encode the following polypeptides: TAN-1, amino acids $19-2555 ; \Delta E C T+S(L)$, amino acids $1673-2555$; $\triangle \mathrm{ECT}-\mathrm{S}(\mathrm{L})$, amino acids $1704-2555$; ICT, amino acids 1768-2555; T3, amino acids $1762-$ 1879; TAR, amino acids 1872-2150. $\Delta \mathrm{L}-\mathrm{S}$ was derived from the full-length cDNA by creating an internal deletion that removed base pairs $4684-5109$ (codons 1562-1703).

Construction and in vitro transcription/translation of a full-length BCL-3 cDNA. An overlapping 3' fragment of the $B C L-3$ cDNA encoding the carboxyl terminus of the protein was PCR amplified from a cDNA library prepared from Jurkat cell poly(A) ${ }^{+}$ RNA. This fragment was ligated to the $5^{\prime}$ end of the
$B C L-3$ cDNA that had been isolated from the human endothelial cell cDNA library. The $B C L-3$ construct was ligated into pBluescript and the structure confirmed by both restriction endonuclease digestion and DNA sequence analysis. Deletion constructs were prepared by PCR of the full-length $B C L-3$ cDNA using appropriate oligonucleotide primer pairs. In vitro transcription with T3 RNA polymerase was performed according to the recommendations of the supplier (Stratagene). In vitro translation of the $B C L-3$ transcripts was performed in a rabbit reticulocyte lysate in the presence of $\left[{ }^{35} S\right]$ methionine according to the recommendations of the manufacturer (Stratagene).

Polypeptide synthesis and antibody preparation. cDNAs encoding the T3 and TAR regions of tan-1 were cloned into the vector pGEX-4T (Pharmacia) and expressed in Escherichia coli as glutathione$S$-transferase (GST) fusion proteins. GST, GST-T3, and GST-TAR were purified from bacterial extracts by affinity chromatography on glutathione-Sepharose columns (Pharmacia). Chickens and rabbits were immunized with purified antigen emulsified in Freund's complete adjuvant and boosted periodically with antigen in Freund's incomplete adjuvant. Serum from immunized chickens and rabbits was cleared of antibody against GST by passage over a GST-AffiGel column (BioRad), and the flowthrough was then applied to AffiGel-GST-T3 or AffiGel-GST-TAR columns. Bound antibody was eluted with $0.2 \mathrm{M}$ glycine ( $\mathrm{pH} 2.7$ ), neutralized with $1 \mathrm{M}$ Tris $(\mathrm{pH} \mathrm{8.0)}$, and dialyzed against PBS.

Transient and stable expression of cDNA. For transient expression studies, cDNAs were cloned into the Bam HI site of the vector pcDNAI (Invitrogen). $293 \mathrm{~T}$ cells were transfected with $\mathrm{CsCl}$-banded DNA using a modified calcium phosphate precipitation method (Pear et al. 1993). For stable expression studies, cDNAs were cloned into the $B c l$ I site of the retroviral shuttle vector pGD (Daley et al. 1990). Helper-free retroviral stocks produced by transfection of the packaging cell line Bosc23 were used to infect NIH-3T3 cells (Pear et al. 1993), and cells containing stably integrated provirus were selected with G418 $(1 \mathrm{mg} / \mathrm{ml})$.

Bone marrow transplantation. Transfection of Bosc23 cells with retroviral vectors, cocultivation of Bosc23 cells and mononuclear cells isolated from 5-FUtreated bone marrow, and injection of infected mononuclear cells into lethally irradiated BALB/cByJ recipients were performed as described previously (Pear et al. 1993).

Preparation and Western blot analysis of protein extracts. Protein extracts were prepared from cell lines and peripheral blood mononuclear cells using RIPA (50 mM Tris [ $\mathrm{pH} 7.4]$ containing $150 \mathrm{~mm} \mathrm{NaCl}, 1$ mm EDTA, 1\% NP-40, 0.5\% sodium deoxycholate, $0.1 \%$ SDS, $10 \mathrm{mg} / \mathrm{ml}$ aprotinin, $10 \mathrm{mg} / \mathrm{ml}$ leupeptin, 1 mM PMSF) by standard methods (Harlow and Lane 1988). For Western blot analysis, proteins were subjected to discontinuous polyacrylamide gel electrophoresis 
(SDS-PAGE) (Laemmli 1970) and transferred to nitrocellulose membranes (Towbin et al. 1979). Blots were blocked and incubated with primary and secondary antibodies as described previously (Dutta et al. 1993). Blots were developed using the ECL method (Amersham).

Western blots using radiolabeled GST-TAR as probe (Far Western blots) were performed on bacterial cell extracts prepared by sonication in the presence of $0.5 \%$ NP-40. Extracts were fractionated by SDS-PAGE and proteins were transferred to nitrocellulose (in the absence of methanol) by electroelution. The filters were blocked with $5 \%$ milk. Proteins were renatured by washing in a decreasing guanidine- $\mathrm{HCl}$ gradient. GSTTAR fusion protein was radiolabeled with ${ }^{32} \mathrm{P}$ and bovine heart muscle kinase according to the method of Kaelin et al. (1992). Binding of radiolabeled GST-TAR was performed overnight at $4^{\circ} \mathrm{C}$ in HYB-75 $(20 \mathrm{~mm}$ HEPES [pH 7.7], $75 \mathrm{~mm} \mathrm{KCl}, 0.05 \%$ NP- $40,0.1 \mathrm{~mm}$ EDTA, $2.5 \mathrm{~mm} \mathrm{MgCl}_{2}$ ) and $1 \%$ milk. Filters were washed in $\mathrm{HYB}-75$ at $4^{\circ} \mathrm{C}$. Identical binding and wash conditions were used to screen the human endothelial cell cDNA library in $\lambda g t 11$ (Blackwood and Eisenman 1991; Kaelin et al. 1992).

Immunoprecipitation of metabolically labeled polypeptides. For standard immunoprecipitations, about $5 \times 10^{6}$ Jurkat or SUP-T1 cells were washed with Hank's buffered saline and incubated twice for 1 hour at $37^{\circ} \mathrm{C}$ in methionine-free RPMI 1640 containing $10 \%$ dialyzed fetal calf serum (Sigma). Cells were then incubated for 3 hours in fresh methionine-deficient media supplemented with $100 \mathrm{mCi}$ to $1 \mathrm{mCi}$ of $\left[{ }^{35} \mathrm{~S}\right]$ methionine (New England Nuclear). For pulsechase analysis, $5 \times 10^{7}$ cells depleted of methionine as described above were resuspended in $8 \mathrm{ml}$ of warm $\left(37^{\circ} \mathrm{C}\right)$ methionine-deficient medium containing $5 \mathrm{mCi}$ of $\left[{ }^{35} \mathrm{~S}\right]$ methionine. After 10 minutes at $37^{\circ} \mathrm{C}$, cells were spun at $500 \mathrm{~g}$ for 5 minutes, washed once with complete medium, and resuspended in $40 \mathrm{ml}$ of complete medium containing $2 \mathrm{~mm}$ unlabeled methionine. At various time points thereafter, $5-\mathrm{ml}$ aliquots were removed and diluted into $15 \mathrm{ml}$ of ice-cold Hank's buffered saline, and then washed once with ice-cold Hank's buffered saline. RIPA extracts prepared from washed cell pellets were "cleared" by mixing for 30 minutes at $4^{\circ} \mathrm{C}$ with $20 \mu \mathrm{l}$ of protein A-Sepharose beads (Pharmacia). After centrifugation, supernatants were incubated with $1 \mu \mathrm{l}$ of rabbit anti-T3 serum for 1 hour at $0^{\circ} \mathrm{C}$, then mixed with $20 \mu 1$ of protein $\mathrm{A}$ Sepharose beads for 30 minutes at $4^{\circ} \mathrm{C}$. Beads were washed 3 times with RIPA and boiled for 10 minutes in $0.1 \mathrm{ml}$ of $0.5 \%$ SDS. Supernatants were adjusted to RIPA conditions (final volume, $0.5 \mathrm{ml}$ ), and cross-reactive polypeptides were reprecipitated as above using $1 \mu l$ of rabbit anti-TAR serum. Control immunoprecipitates were prepared by sequential incubation with pre-immune sera.

Peptide mapping. Proteins were metabolically labeled with $\left[{ }^{35} \mathrm{~S}\right]$ methionine, immunoprecipitated, and subjected to discontinuous SDS-PAGE. After visualiza- tion of the position of bands by fluorography, onedimensional peptide maps were prepared from excised bands using V8 protease (Cleveland et al. 1977).

Immunolocalization. For immunoperoxidase staining, $1 \times 10^{4}$ SUP-T1 or Jurkat cells were deposited on slides by cytocentrifugation. For immunofluorescent staining, cells were grown on 8-chamber slides (LabTek, Permanox). In each case, cells were fixed in $2 \%$ paraformaldehyde, permeabilized in $-20^{\circ} \mathrm{C}$ methanol, and stained with affinity-purified rabbit anti-tan- 1 antibodies using previously described incubation and washing conditions (Pinkus et al. 1985).

\section{RESULTS}

\section{Structural Analysis of tan-1 in Cells with and without the $t(7 ; 9)$}

To investigate the structure of the tan-1 proteins produced in cells containing or lacking the $t(7 ; 9)(q 34 ; q 34.3)$, antibodies raised against portions of the cytoplasmic domain of tan-1 were used in Western blot analysis of whole-cell extracts prepared from SUPT1 and Jurkat cells (Fig. 2). SUP-T1 is a cell line established from a T-lineage lymphoblastic lymphoma that contained two identical copies of the $t(7 ; 9)$ (q34; $\mathrm{q} 34.3$ ), no normal chromosome 9, and therefore no normal copy of $T A N-1$. Jurkat, a control cell line also derived from a $\mathrm{T}$-lymphoblastic tumor, lacks any

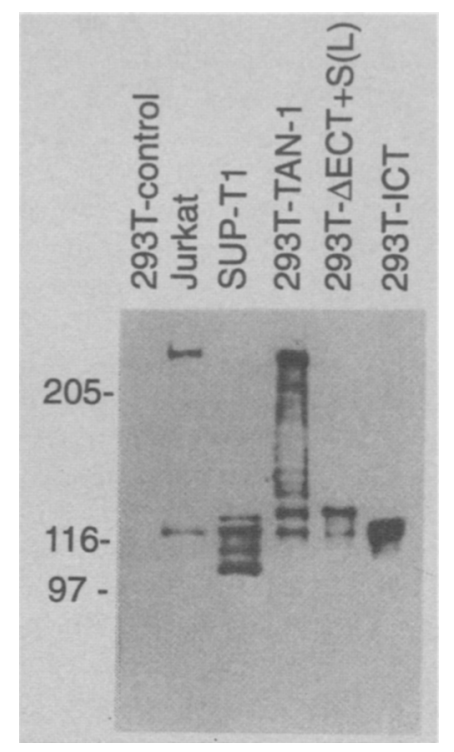

Figure 2. Western blot of cross-reacting polypeptides detected with anti-tan-1 antibodies. Whole-cell protein extracts from Jurkat cells (50 $\mu \mathrm{g}$ of protein), SUP-T1 cells $(50 \mu \mathrm{g})$, or 293T cells $(500 \mathrm{ng})$ transiently transfected with empty vector or vector carrying $T A N-1$ cDNAs were fractionated by SDSPAGE in $6 \%$ gels prior to electrophoretic transfer to nitrocellulose. After incubation with affinity-purified chicken antiT3 antibody $(1 \mu \mathrm{g} / \mathrm{ml})$ and secondary rabbit anti-chicken antibody linked to horseradish peroxidase $(1: 2500)$, cross-reactive polypeptides were detected using chemiluminescence. The positions of size markers are shown in kilodaltons at the left. 
known abnormality of chromosome 9 or $T A N$-1. Initial studies performed with antibodies raised in chickens against a portion of the cytoplasmic domain close to the transmembrane domain (termed T3; see Fig. 1) detected a series of bands in SUP-T1 extracts corresponding to polypeptides of $\sim 125-100 \mathrm{kD}$. This antibody also detected two major bands in Jurkat extracts-one band corresponding to a large polypeptide of $\sim 350 \mathrm{kD}$ (hereafter referred to as $\mathrm{p} 350$ ) and a second band corresponding to a smaller polypeptide of $\sim 120 \mathrm{kD}$ (referred to as p120). The size of the p350 polypeptide is compatible with that predicted for the full-length tan-1 protein, and the size of the p120 polypeptide matches that observed for one of the major truncated products present in SUP-T1 cells.

Other antisera raised in chickens and rabbits against $\mathrm{T} 3$ and the region (termed TAR) containing a series of six so-called ankyrin-like repeats also recognized p350 and $\mathrm{p} 120$ in extracts from Jurkat cells and polypeptides of $100-125 \mathrm{kD}$ in extracts from SUP-T1 cells (not shown), suggesting that these polypeptides are encoded by the wild-type and $\mathrm{t}(7 ; 9)(\mathrm{q} 34 ; \mathrm{q} 34.3) T A N-1$ alleles, respectively. The specificity of various antibodies was confirmed in several ways. The polypeptides detected with affinity-purified antibodies against tan-1 were not stained by pre-immune sera, and staining with specific antibody was inhibited by pre-incubation with purified antigen. Furthermore, Western blots of extracts from 293T cells transiently transfected with expression vectors containing full-length $T A N-1$ cDNAs showed greatly increased levels of cross-reacting polypeptides.

To characterize the structure of the various crossreactive polypeptides found in Jurkat and SUP-T1 cells, full-length $T A N-1$ cDNAs and cDNAs carrying deletions from the $5^{\prime}$ end of the gene were transiently transfected into 293T cells (Figs. 1 and 2). Transfection with the full-length cDNA resulted in expression of a series of polypeptides, the most prominent of which was close to the size of $\mathrm{p} 350$. In contrast, the sizes of the largest of the SUP-T1 polypeptides and p120 were similar to sizes of polypeptides encoded by cDNAs with deletions removing most of the coding sequence for the extracellular domain of tan-1. To further study the structural similarities between polypeptides, a method for specific immunoprecipitation of cross-reactive polypeptides was developed (Fig. 3A). Partial digestion of ${ }^{35}$ S-labeled immunoprecipitated proteins with V8 protease generated a set of comparable bands in onedimensional gels from $\mathrm{p} 120$ and several of the truncated polypeptides of SUP-T1 (Fig. 3B). Therefore, the compositions of p120 and the truncated polypeptides associated with chromosomal translocation appear similar. Partial digestion of a polypeptide precipitated from $293 \mathrm{~T}$ cells transfected with a truncated cDNA construct, $\triangle \mathrm{ECT}-\mathrm{S}(\mathrm{L})$, yielded a one-dimensional map closely corresponding to that of p120 and the largest truncated polypeptides of SUP-T1. This expression construct encodes a mature polypeptide with an amino terminus at codon 1703, a position 30 amino acids external to the transmembrane domain and just inter-

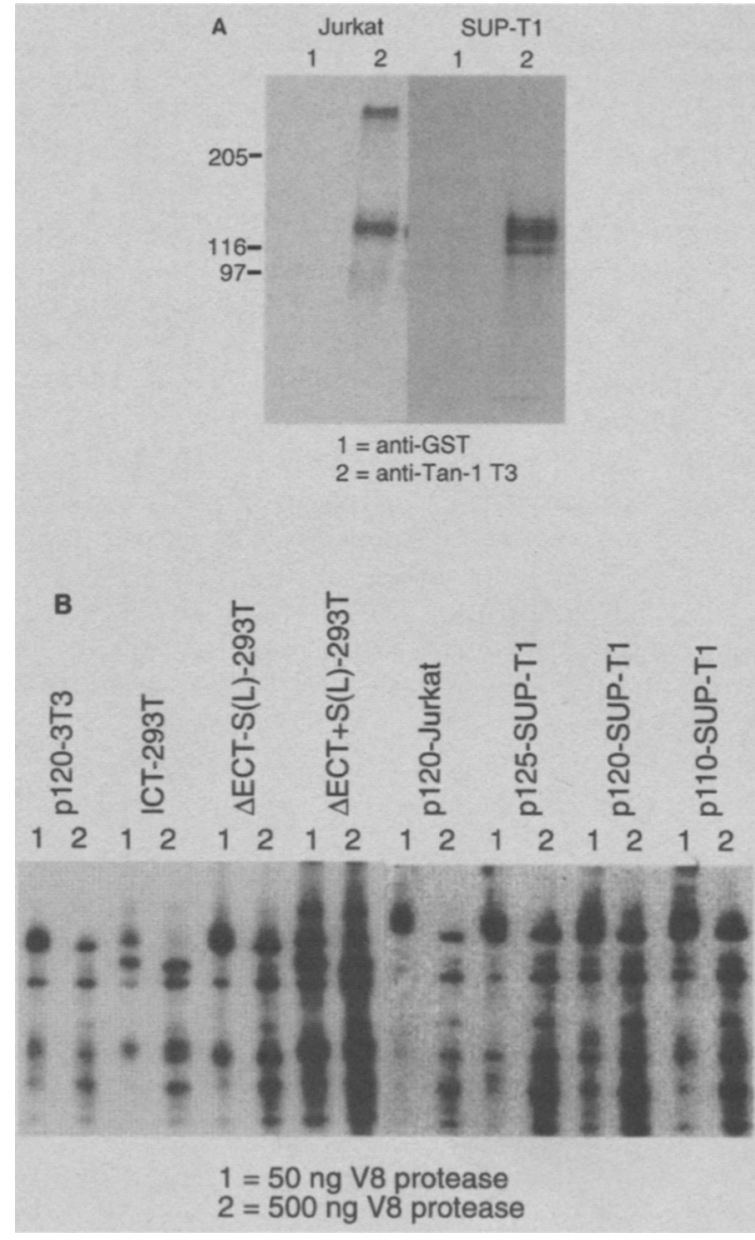

Figure 3. Peptide mapping of tan-1-related polypeptides. $(A)$ Immunoprecipitations of tan-1 polypeptides from extracts of Jurkat and SUP-T1 cells. Cells were metabolically labeled with $\left.{ }^{35} \mathrm{~S}\right]$ methionine and proteins were immunoprecipitated with rabbit anti-T3 antiserum, followed by resolubilization of complexes by boiling and reprecipitation with rabbit anti-TAR antiserum. Control immunoprecipitations were performed with rabbit anti-GST antiserum during the first stage. Results were analyzed by SDS-PAGE in a $6 \%$ gel and fluorography of the gel. Comparison to the results in Fig. 2 demonstrates the specificity of sequential immunoprecipitation using the two antisera. ( $B$ ) Peptide mapping of immunoprecipitated protein performed as in $A$. Immunoprecipitation was carried out on the NIH-3T3 cells infected with pGD-TAN-1, transiently transfected 293T cells, and Jurkat and SUP-T1 cells metabolically labeled with $\left[{ }^{35} \mathrm{~S}\right]$ methionine. Precipitated polypeptides were separated by SDS-PAGE, located by fluorography, excised from the gel, and subjected to partial proteolysis with 50 $\mathrm{ng}$ or $500 \mathrm{ng}$ of $\mathrm{V} 8$ protease during electrophoresis in $12 \%$ polyacrylamide gels.

nal to two conserved cysteine residues encoded by codons 1683 and 1690. Maps of polypeptides from cells transfected with cDNA constructs including more or less coding sequence near this site (e.g., $\Delta \mathrm{ECT}+\mathrm{S}[\mathrm{L}]$ and ICT) differed from maps of p120 and the truncated polypeptides. Therefore, the amino terminus of $\mathrm{p} 120$ and the largest truncated polypeptides in SUP-T1 are very close and possibly just carboxy-terminal to the two conserved cysteines. 
These data show that the size and structure of the tan-1 polypeptides found in extracts of SUP-T1 are consistent with translation of polypeptides from a truncated TAN-1 transcript. Northern blot analyses of SUP-T1 cells have shown the presence of abundant novel mRNA species that are derived from the $3^{\prime}$ portion of $T A N-1$ and vary from 4 to $6 \mathrm{~kb}$ (Ellisen et al. 1991), suggesting activation of cryptic promoters in DNA near the breakpoint. The exact positions of the transcriptional start sites are not known and could be either $5^{\prime}$ or $3^{\prime}$ of the breakpoint. The precise translational start site or sites are also uncertain. The translocation breakpoint in SUP-T1 cells and two other tumors containing the $t(7 ; 9)(q 34 ; q 34.3)$ lie in an intron within DNA encoding EGF repeat 34 , such that the first in-frame codon $3^{\prime}$ of the breakpoint in all tumors begins at bp 4015 of the cDNA (Ellisen et al. 1991). Transfection of 293T cells with a cDNA beginning at bp 4015 and continuing through the $3^{\prime}$ stop codon results in synthesis of several polypeptides of lower abundance, which are larger than those seen in SUP-T1 cells (not shown). This suggests that sequences $3^{\prime}$ of the breakpoint that normally are intronic may contribute one or more translational start sites, and raises the possibility that some of the cross-reactive polypeptides in SUP-T1 cells have sequences at their amino termini found nowhere in the full-length protein. If such sequences exist, however, they are not required for oncogenesis (see below).

The results of Western blots and peptide mapping suggested that $\mathrm{p} 120$ is generated by proteolytic cleavage of $\mathrm{p} 350$. This interpretation is consistent with the presence of a band at the $120 \mathrm{kD}$ position in blots of extracts from $293 \mathrm{~T}$ cells and NIH-3T3 cells transiently or stably overexpressing full-length $T A N-1$ cDNA, respectively. Northern blots of Jurkat RNA also support this interpretation, since these analyses fail to show $T A N-1$ transcripts other than the $8.2-\mathrm{kb}$ species. Therefore, translation of p120 from either an alternatively spliced mRNA or a transcript originating from a second internal promoter is unlikely.

To confirm that p350 is the precursor of $\mathrm{p} 120$, a pulse-chase analysis was performed with Jurkat cells. This demonstrated a clear inverse relationship between the amount of $\mathrm{p} 350$ and $\mathrm{p} 120$, with progressively more p120 accumulating over time (Fig. 4A). These results are compatible with the derivation of p120 from p350 by proteolytic cleavage. On the basis of peptide map data, it was predicted that this cleavage site should be just external to the transmembrane domain. This conclusion is supported by inhibition of proteolytic processing by a deletion removing the amino acid sequence between the lin- 12 repeats and the transmembrane domain (Fig. 4B).

\section{Analysis of the Subcellular Location of tan-1}

The location of tan-1 proteins within cells was studied by immunofluorescence and immunohistochemistry using the anti-T3 and anti-TAR antibodies.

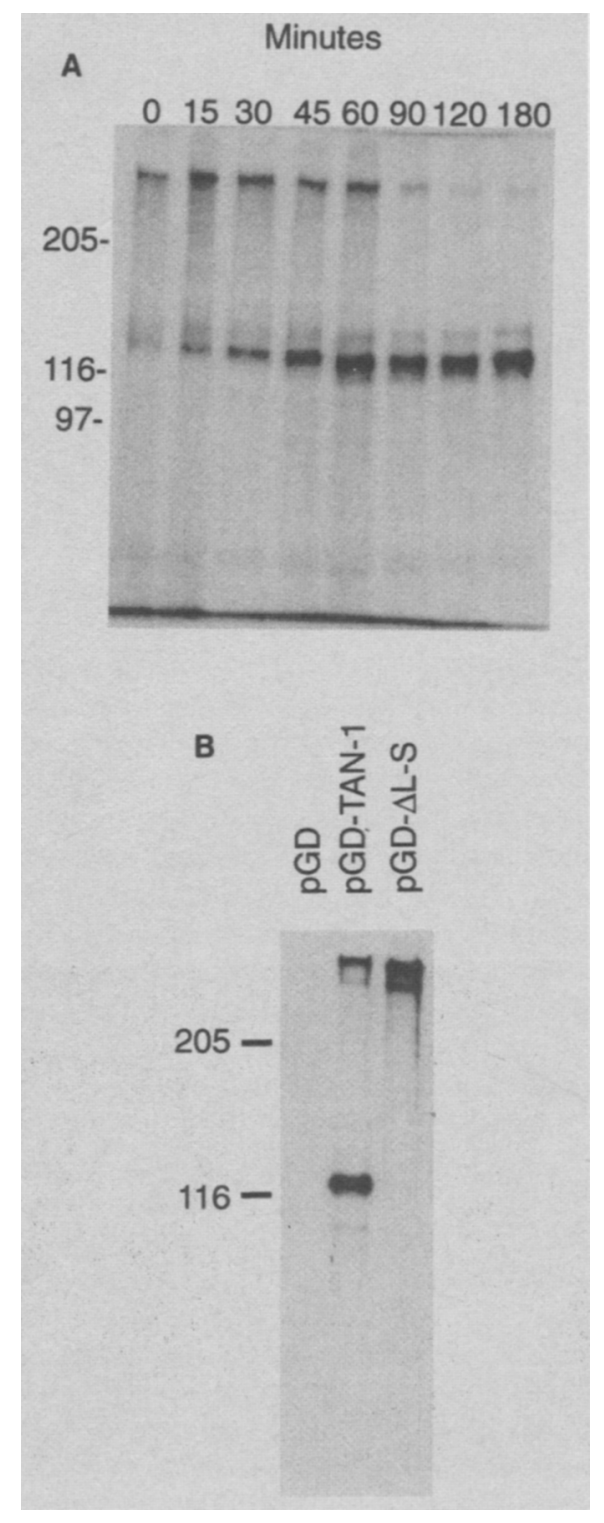

Figure 4. Processing of full-length tan-1 protein. $(A)$ Pulsechase analysis. Jurkat cells were metabolically labeled with $\left[{ }^{35} \mathrm{~S}\right]$ methionine for $10 \mathrm{~min}$, resuspended in medium containing unlabeled methionine, and harvested thereafter at intervals shown at the top of the figure. Polypeptides were immunoprecipitated and analyzed as in Fig. 3A. (B) Western blot analysis of NIH-3T3 cells stably expressing tan-1 from retroviral vectors. Whole-cell extracts were prepared from cells infected by the pGD vector containing no cDNA insert, a full-length $T A N-1$ cDNA, or a $T A N-1$ cDNA deleted for a region lying between the lin-12 repeats and the transmembrane domain $(\Delta \mathrm{L}-\mathrm{S})$. From each extract, $10 \mu \mathrm{g}$ was analyzed, using chicken anti-T3 antibody as in Fig. 2.

Because cells lacking the $t(7 ; 9)(q 34 ; q 34.3)$ showed only weak staining with these reagents, attempts were made to determine the normal location of tan-1 by infecting NIH-3T3 cells with a recombinant retrovirus that produces relatively large amounts of p350 and processed $\mathbf{p} 120$. This procedure resulted in staining of the cytoplasm in a speckled, perinuclear pattern, suggesting 
localization to the endoplasmic reticulum (Fig. 5A). The N-linked glycosyl residues of p350 were also found to be endoH-sensitive (J. Aster and J. Sklar, unpubl.), further supporting retention of tan-1 in the endoplasmic reticulum. Similar cytoplasmic retention of notch has been demonstrated in overexpressing insect cells, although both notch and tan-1 are predicted to function as transmembrane receptors and therefore to be expressed on plasma membrane. These findings indicate that surface expression of tan-1 and notch may be tightly regulated and dependent on cofactors which have yet to be discovered.

In contrast to the cytoplasmic location of $\tan -1$ in cells expressing full-length tan-1, cross-reacting polypeptides were found predominantly in the nuclei of SUP-T1 cells (Fig. 5B). This staining pattern was also observed in $293 \mathrm{~T}$ cells transiently expressing the cytoplasmic domain (ICT) of tan-1 (Fig. 5C). Since the polypeptides expressed in SUP-T1 lack signal peptides, insertion of these polypeptides into membranes may occur inefficiently or not at all, thereby explaining the difference in subcellular localization of these polypeptides and polypeptides encoded by the $\triangle \mathrm{ECT}(\mathrm{L})$ ex- pression constructs. Taken together, these findings imply that signals permitting efficient nuclear transport exist within the intracellular portion of $\tan -1$. Four short stretches of intracellular sequence relatively rich in basic amino acids represent potential nuclear localization signals (NLSs). The first two of these lie within the $\mathrm{T} 3$ region of the protein, and the other two lie just carboxy-terminal to the ankyrin repeats. Deletion of both of these regions led to retention of most of the tan-1 polypeptide in the cytoplasm (Fig. 5D). Deletion of either region separately was much less effective in causing the redistribution of protein from nucleus to cytoplasm, indicating an additive effect of NLSs in these two regions.

\section{In Vivo Transformation of Murine Bone Marrow Stem Cells by $T A N-I$ cDNA}

The role of tan-1 protein in malignant transformation was directly tested by transduction of truncated $T A N-1$ cDNAs into murine bone marrow cells and infusion of these cells back into lethally irradiated syngeneic mice. Two cDNA constructs, $\triangle \mathrm{ECT}+\mathrm{S}(\mathrm{L})$ and $\triangle \mathrm{ECT}-\mathrm{S}(\mathrm{L})$,
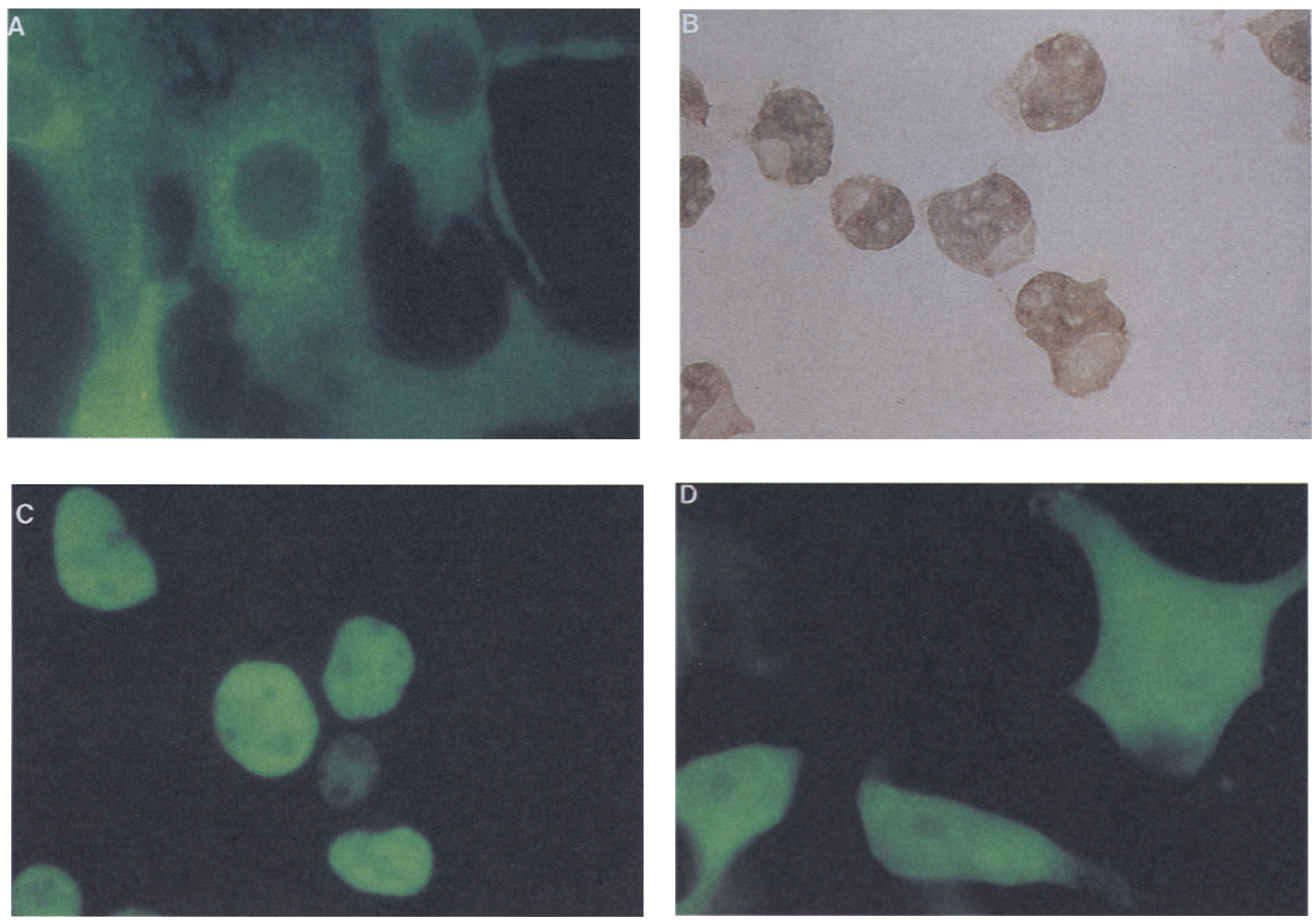

Figure 5. Immunolocalization of tan-1 polypeptides within tissue culture cells. $(A)$ NIH-3T3 cells infected with the retrovirus pGD-TAN-1, overexpressing full-length tan-1; $(B)$ SUP-T1 cells; $(C)$ 293T cells transiently transfected with expression vectors carrying a cDNA construct for the cytoplasmic domain of $T A N-1$ (ICT); and $(D)$ 293T cells transiently transfected with an expression vector identical to that in $C$, except for the deletion from the $T A N-1$ coding sequence of two putative nuclear localization signals (ICT $\Delta \mathrm{T} 3 \Delta \mathrm{N} 2$ ). Cells in each panel were stained with affinity-purified rabbit anti-T3 or anti-TAR antibodies, followed by sheep anti-rabbit antibody linked to fluorescein thiocyanate $(A, C$, and $D)$ or goat anti-rabbit antibody linked to horseradish peroxidase $(B)$. Cells in $A, C$, and $D$ were photographed through a fluorescence microscope. Cells in $B$ were photographed through a standard visible light microscope after developing the image by incubation with diaminobenzidine and counterstaining with methyl green. Magnification, $650 \times$. 
were inserted into the retroviral shuttle vector pGD, which was transfected into the packaging cell line Bosc23. Bone marrow mononuclear cells were infected with the resultant helper-free retrovirus by co-cultivation with the Bosc23 cells. Following transplantation, mice were monitored by biweekly bleeding and by observation for cachexia. Mice with significantly elevated leukocyte counts or grossly apparent disease were sacrificed and autopsied.

To date, 7 of 20 mice have developed leukemia with a latency of between 11 and 40 weeks posttransplantation. Mice that developed leukemia were observed with both cDNA constructs (Table 1). Flow cytometry indicated that the leukemic cells in each case had an antigenic profile compatible with an immature T-cell phenotype. All tumors have proven to be readily transplantable into syngeneic recipients, and one stable cell line has been derived (T6E).

Immunostaining of various tissues with tan- 1 antibodies demonstrated high levels of cross-reactive protein in infiltrating tumor cells relative to surrounding normal tissue (not shown). To determine the intracellular distribution of staining, additional immunohistochemistry was performed on cytospin preparations of the T6E cell line and disaggregated tumors. This analysis revealed most staining to be cytoplasmic in a vesicular, perinuclear distribution, with less intense nuclear membrane staining evident in a subset of cells (Fig. 6A). The precise identity of the vesicular structures is not yet known. Western blot analysis performed on extracts of these tissues with anti-T3 and anti-TAR antibodies detected one to several prominent bands at the position of polypeptides of about $120 \mathrm{kD}$, the approximate size of the products expected to be synthesized from the $\Delta \mathrm{ECT}+\mathrm{S}(\mathrm{L})$ and $\triangle \mathrm{ECT}-\mathrm{S}(\mathrm{L})$ cDNA constructs (Fig. 6B). Additionally, particularly in extracts prepared from the $\mathrm{T} 6 \mathrm{E}$ cell line, a band of about $350 \mathrm{kD}$ was also present, corresponding to the size of full-length notchrelated proteins. Further work has shown that this band also cross-reacts with an antibody directed against a region just amino-terminal of the opa sequence ( $\mathrm{J}$. Aster et al., unpubl.). This region is found in murine tan-1 (notch1), but is absent from notch2, notch3, and int-3, suggesting that the cross-reactive band is the product of endogenous murine Notchl. It is unclear
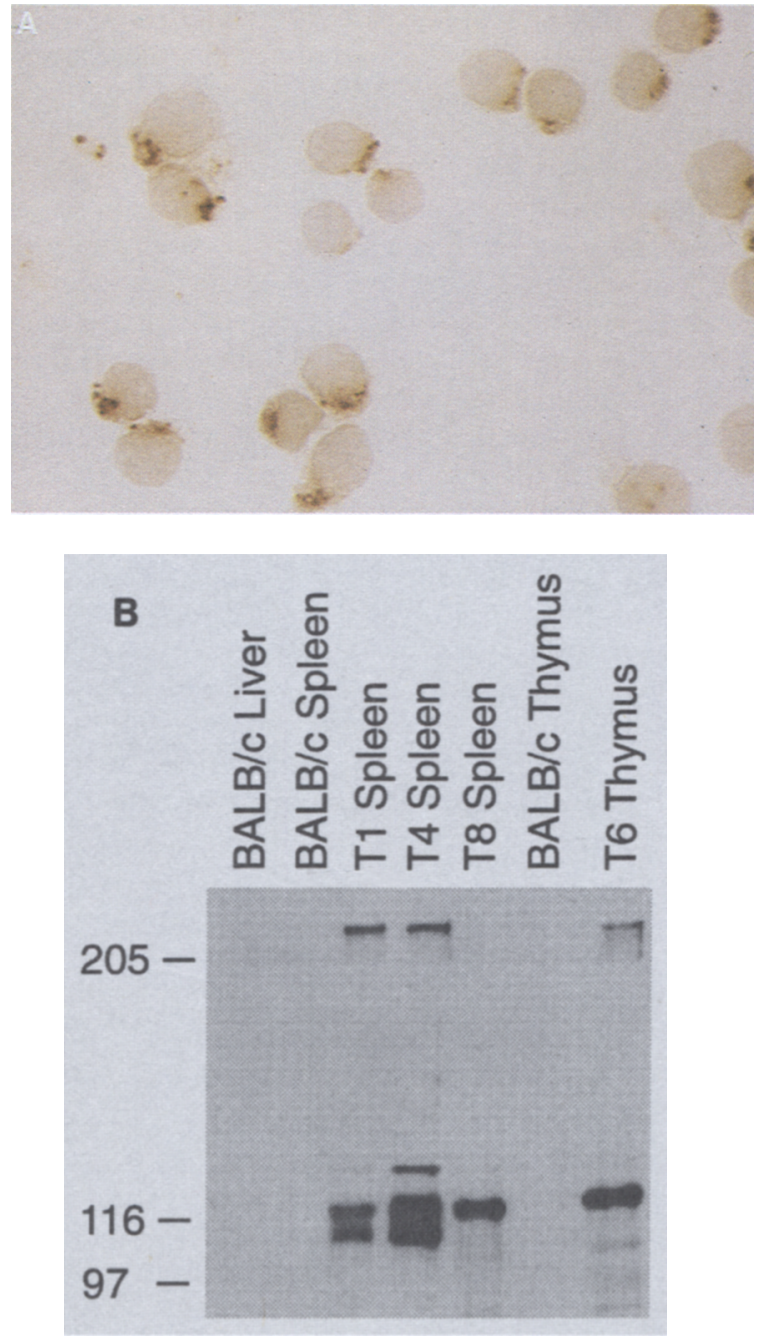

Figure 6. Analysis of tan-1 polypeptide in murine leukemias induced by infection of bone marrow cells with retroviral vectors carrying deleted forms of the TAN-1 cDNA. $(A)$ Immunolocalization of tan-1 polypeptide in the $\mathrm{T} 6 \mathrm{E}$ in vitro cell line. The cells were stained with rabbit anti-T3 antibody and the image was developed and photographed as in Fig. 5B. Magnification, $650 \times$. (B) Western blot analysis of extracts prepared from organs of leukemic mice which showed heavy visceral involvement by tumor and from organs of normal $\mathrm{BALB} / \mathrm{c}$ control animals. T1, 4, 6, and 8 correspond to the designations in Table 1 . Ten $\mu \mathrm{g}$ from each extract were analyzed in Western blots using rabbit anti-T3 antibody.

Table 1. Characteristics of Lymphoblastic Neoplasms Arising in Mice Which Underwent Transplantation with Bone Marrow Infected with Retroviral Vectors Carrying $\triangle \mathrm{ECT}+\mathrm{S}(\mathrm{L})$ and $\triangle \mathrm{ECT}-\mathrm{S}(\mathrm{L})$ cDNAs.

\begin{tabular}{|c|c|c|c|c|c|c|c|c|c|c|c|c|}
\hline \multirow[b]{2}{*}{$\begin{array}{l}\text { Animal } \\
\#\end{array}$} & \multirow[b]{2}{*}{$\begin{array}{c}\text { Cys } \\
\text { repeats }\end{array}$} & \multirow[b]{2}{*}{$\begin{array}{l}\text { latency } \\
\text { (weeks) }\end{array}$} & \multirow[b]{2}{*}{$\begin{array}{c}\text { Terminal } \\
\mathrm{WBC}(\mathrm{k} / \mu \mathrm{l})\end{array}$} & \multicolumn{4}{|c|}{ Sites of gross involvement } & \multicolumn{4}{|c|}{ FACS } & \multirow[b]{2}{*}{$\begin{array}{c}2^{\circ} \\
\text { mice }\end{array}$} \\
\hline & & & & node & spleen & liver & thymus & CD3 & $\mathrm{CD} 4$ & $\mathrm{CD} 8$ & $\beta$ & \\
\hline $\mathrm{T} 1$ & - & 11 & 70 & + & + & - & - & + & + & + & + & + \\
\hline $\mathrm{T} 3$ & - & 16 & 4 & - & - & - & - & + & - & + & + & + \\
\hline $\mathrm{T} 4$ & - & 12 & 68 & + & + & + & - & + & + & + & + & + \\
\hline T6 & + & 15 & 42 & + & + & - & + & + & - & + & + & + \\
\hline$T 7$ & + & 40 & 65 & + & + & + & + & n.d. & - & - & n.d. & n.d. \\
\hline T8 & + & 15 & 41 & + & + & - & - & + & + & + & + & + \\
\hline T14 & + & 16 & 55 & + & + & - & - & + & + & + & + & + \\
\hline
\end{tabular}

The first three mice received $\Delta E C T-S(L)$ (indicated by - in the second column) and the next four $\Delta E C T+S(L)$ (indicated by + in the second column). FACS $=$ results of flow cytometry. n.d. $=$ not done. $\mathrm{WBC}=$ white blood cell count. $\beta=\mathrm{T}$-cell receptor $\beta$ chain. 
whether expression of notch 1 is due to induction by the truncated tan-1 protein or to the selective transformation of T-cell precursors in which the gene is normally expressed.

Southern blot analysis with probes specific for the retroviral vector sequences has shown that six of seven tumors analyzed contain a single integrated provirus, with the seventh having two proviruses (not shown). Southern blot analyses showed that all sites of insertion into the genome were unique. Additionally, analyses with $\mathrm{J} \beta 1$ and $\mathrm{J} \beta 2$ probes indicated that all tumors except for that in animal T6 had clonal rearrangements of the $\beta \mathrm{T}$-cell-receptor gene.

These studies demonstrate that tumors arising in recipients of marrow infected with retrovirus carrying truncated forms of TAN-1 develop clonal T-lymphoblastic neoplasms at high frequency. An additional seven tumors have now been observed in other transplant cohorts, all of which have also demonstrated an immature T-cell phenotype (W.S. Pear et al., unpubl.), further emphasizing the T-cell oncotropism of $T A N-1$. In contrast, of approximately 200 animals receiving marrow transduced with pGD carrying other cDNA constructs, none has developed a T-cell tumor (W.S. Pear et al., unpubl.). Although recombination of defective retrovirus with an endogenous provirus to produce competent Moloney leukemia virus is a theoretical concern, transcripts encoding the Moloney envelope have not been detected in leukemic animals (W.S. Pear et al., unpubl.), making this possibility unlikely.

\section{Identification of an Intracellular Ligand of tan-1 Protein}

The presence of both large extracellular and intracellular domains within the tan-1 protein suggests that this molecule may mediate the transduction of some signal across the plasma membrane by binding or interacting with ligands on either side of the membrane. Indeed, in Drosophila, direct physical interaction has been demonstrated between the extracellular portion of notch and the protein products of two genes, Delta and Serrate (Rebay et al. 1991). Our initial efforts to identify ligands of tan- 1 have concentrated on the intracellular region of the molecule. Since ankyrin repeats have been implicated previously in interactions between other proteins (Lux et al. 1990; Nolan and Baltimore 1992), we have searched for ligands that might bind to the region of tan-1 containing these repeats.

A 750-bp fragment encoding the ankyrin repeats (TAR) was amplified by PCR from the cloned TAN-1 cDNA, ligated into the bacterial glutathione- $S$-transferase (GST) expression plasmid pGEX2TK, and expressed in E. coli as a fusion polypeptide with GST at the amino terminus. The GST-TAR fusion polypeptide labeled with ${ }^{32} \mathrm{P}$ was then used to screen plaques for TAR-binding proteins from a human endothelial cell cDNA library cloned in $\lambda \mathrm{gt} 11$ (Ginsburg et al. 1985). This randomly primed cDNA library was chosen for screening because it is known to be highly representa- tive of a vast array of RNAs and because it is the same library from which cDNA on the 5' end of the TAN-1 mRNA was originally isolated (Ellisen et al. 1991). Several plaques showed binding of the GST-TAR fusion polypeptide in this assay. Bacteriophage from the single plaque that continued to show binding after three rounds of screening were purified, and the nucleotide sequence of the cDNA inserted within the vector DNA was determined. Comparison of sequences in the GenBank database demonstrated a match between the isolated cDNA and a large $5^{\prime}$ fragment of the coding sequence for the gene $B C L-3$.

To confirm the binding of the GST-tan-1 fusion polypeptide to bcl-3, portions of the $B C L-3$ cDNA were inserted into the pGEX2TK plasmid, and GSTbcl-3 fusion polypeptides were expressed in E. coli. Protein extracts from these bacteria were separated in SDS-polyacrylamide gels and transferred to nitrocellulose membranes. The membranes were then incubated with radiolabeled GST-TAR fusion polypeptide. Autoradiograms of the membranes revealed that the GSTTAR polypeptide had specifically bound the aminoterminal fragment of bcl-3 protein containing the first six of the seven ankyrin repeats found in bcl-3 (Fig. 7A). As few as three bcl-3 ankyrin repeats were sufficient for some residual binding by GST-TAR. To demonstrate that the interaction between TAR and bcl-3 polypeptides was not due to an artifact arising from truncations of the bcl-3 polypeptide, full-length bcl-3 radiolabeled with $\left[{ }^{35} \mathrm{~S}\right]$ methionine was synthesized in vitro. Bcl-3 protein synthesized in this fashion bound to GST-TAR glutathione-Sepharose beads, but not GST glutathione-Sepharose beads (Fig. 7B).

Direct co-immunoprecipitation of tan-1/bcl-3 complexes with anti-tan-1 and/or anti-bcl-3 antibodies from tissue culture cells was complicated by the low amounts of bcl-3 produced in most cells and by the low affinity of the anti-bcl-3 antibodies which we have either produced ourselves or obtained from other sources. To overcome the problem of low antigen concentration within cells, we have conducted co-immunoprecipitation studies using transfected $293 \mathrm{~T}$ cells co-expressing epitope-tagged bcl-3 and various forms of tan-1. For these studies, the $B C L-3$ cDNA was inserted into the vector pCGN, which produces a fusion polypeptide containing an epitope from the influenza virus hemagglutinin (HA) at the amino terminus of the fusion protein. Immunoprecipitates of extracts from the doubly transfected cells using the mouse monoclonal antibody 12CA5, which recognizes the HA epitope, brought down $\mathrm{p} 350$ together with p120 tan-1 polypeptides presumably bound to the HA-bcl-3 fusion protein (Fig. 7C). These data demonstrate that interaction of tan- 1 and bcl- 3 can occur in intact cells.

\section{Evidence of a Possible Role for $\tan -1$ in Transcriptional Activation}

We unexpectedly uncovered evidence suggesting a possible role for $\tan -1$ in transcriptional activation 


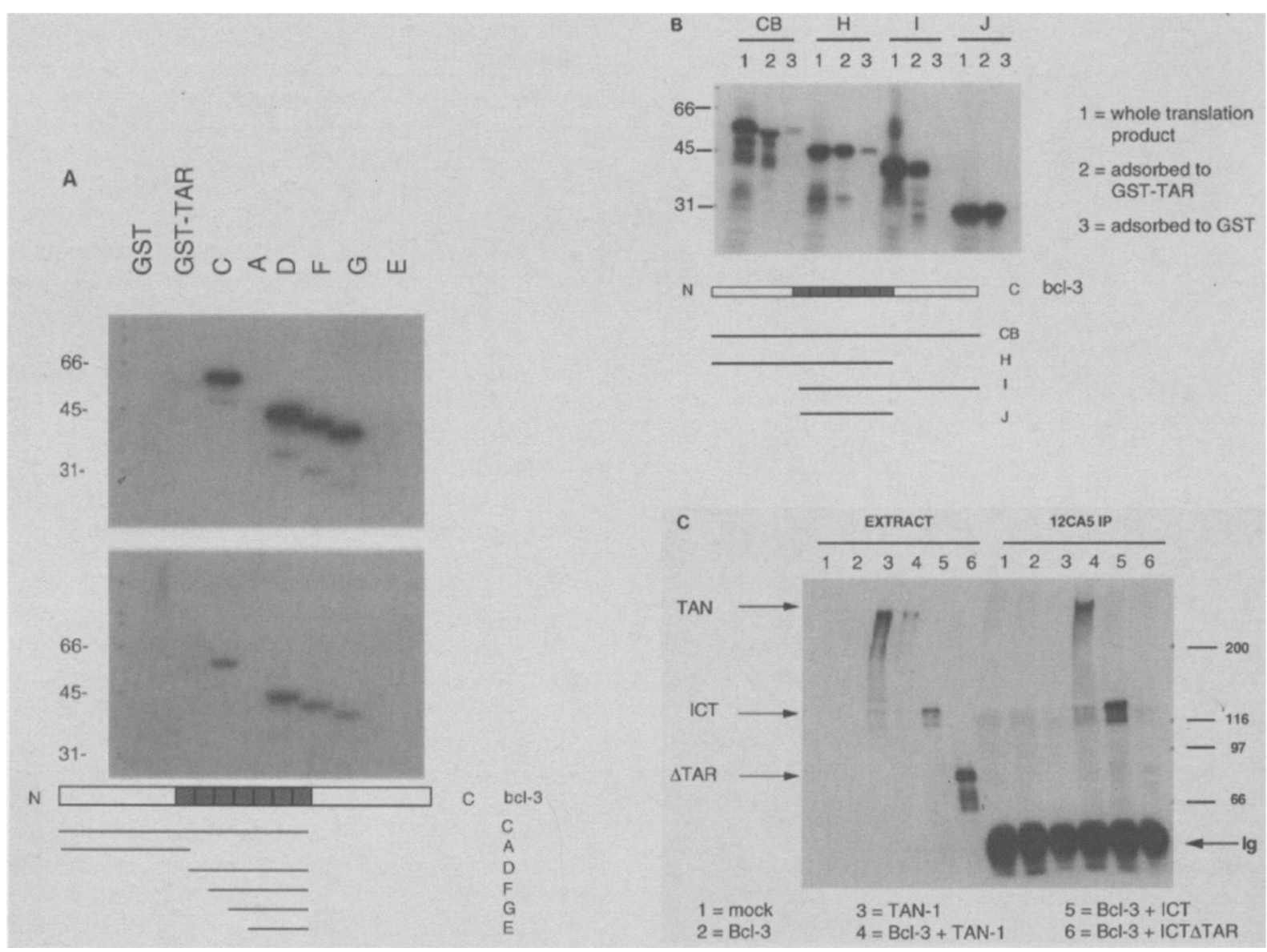

Figure 7. Analysis of protein-protein interactions between tan-1 and bcl-3. (A) Far Western blot of GST-bcl-3 polypeptides expressed in $E$. coli, using radiolabeled GST-TAR as a probe. Protein extracts from $400 \mu$ saturated bacterial cultures were loaded in each lane; Coomassie blue staining of a duplicate gel showed equivalent amounts of protein in the lanes. To demonstrate the specificity of binding, the membrane in the top panel was incubated with probe in the presence of unlabeled GST and in the lower panel in the presence of unlabeled GST-TAR. At the bottom are shown fragments of bcl-3 joined to GST in various fusion polypeptides analyzed. The seven tandem ankyrin repeats in bcl-3 are indicated by shaded boxes. $(B)$ Adsorption of ${ }^{35} S$-labeled bcl-3 polypeptide translated in vivo to GST or GST-TAR bound to glutathione-Sepharose beads. In vitro translation products were separated by SDS-PAGE in a $6 \%$ gel immediately following translation (lane 1 ) or after adsorption to glutathione-Sepharose beads preloaded with either GST-TAR (lane 2) or GST alone (lane 3). For lanes 2 and 3 , fivefold more translation product was incubated with the beads as compared to the amount of product loaded directly in lane 1 . The gel was dried and fluorographed. $(C)$ Co-immunoprecipitation of $\tan -1$ and epitope-tagged bcl-3 polypeptides from transfected cells. 293T cells were infected with pCGN-HA-BCL-3 and/or pCGN-TAN-1 expression vectors, some of which contained deletions in the TAN-1 cDNA. NP-40 extracts were prepared after two days of culture, and HA-bcl-3 fusion polypeptide was precipitated with the 12CA5 antibody directed against the HA epitope. Whole extracts (left) and immunoprecipitates (right) were analyzed by Western blotting as in Fig. 2. 25-fold more extract was used for immunoprecipitation compared to the amounts of whole extract loaded directly on the gel.

when we attempted to utilize the so-called yeast twohybrid system (Zervos et al. 1993) to identify intracellular ligands of tan-1. In preparation for using the twohybrid system, we found that a "bait" plasmid expressing a portion of the cytoplasmic domain of tan-1 (including the ankyrin repeats) fused to the DNA-binding protein LexA showed significant transcriptional activation of a $\beta$-galactosidase reporter gene. In fact, the degree of activation was in the range produced by a LexA-gal4 fusion protein, a natural strong transcriptional activator in Saccharomyces cerevisiae (Table 2). On the basis of these results, the intracellular domain of tan-1 apparently has the capacity, by itself, to activate transcription in yeast when it is supplied with the proper DNA-binding site.

\section{DISCUSSION}

Our studies have established several major points about $T A N-1$ and have also yielded a number of paradoxical observations. As demonstrated by experiments in which cDNA fragments of the $T A N-1$ gene were transduced into murine bone marrow cells that were then infused into irradiated hosts, truncated forms of the gene have potent oncogenic activity and exhibit a striking oncotropism for T-cell precursors. This ob- 
Table 2. Transcription Activation by $T A N-1$ cDNA Fragments in the Yeast Two-hybrid System

\begin{tabular}{lc}
\hline & $\beta$-Galactosidase \\
\hline$L E X A$ & 5,1 \\
LEXA-GAL4 & 1196,1744 \\
LEXA-TAN-1 $1760-2124$ & 1596,759 \\
\hline
\end{tabular}

On the left is the DNA insert ligated into the bait plasmid of the yeast two-hybrid system. $L E X A$ is the coding sequence for the $E$. coli DNA-binding protein. $G A L 4$ is the full-length cDNA of the $S$. cerevisiae transcription factor. TAN-1 $1760-2124$ is the portion of the TAN-1 cDNA containing codons $1760-2124$ of the $\tan -1$ protein (a region beginning on the intracellular side of the transmembrane domain and ending just carboxy-terminal to the ankyrin repeats. Each of these constructs was expressed in yeast and scored for the ability to increase the expression of a $\beta$-galacosidase reporter gene (Zervos et al. 1993). $\beta$-Galactosidase activity was measured in arbitrary optical units The results of two separate cultures for each bait plasmid are shown.

servation confirms the inference that the $3^{\prime}$ portion of this gene is related to the primary transforming event in the leukemia of those patients whose malignant $\mathrm{T}$ cells carry the $t(7 ; 9)(\mathrm{q} 34 ; \mathrm{q} 34.3)$. The frequency with which the recipient mice developed leukemia suggests that the oncogenic potential of this gene is high despite the fact the $t(7 ; 9)(q 34 ; q 34.3)$ occurs only in a minority of T-cell lymphoblastic neoplasms. However, the precise efficiency of truncated $T A N-1$ in inducing transformation cannot be determined, since we do not yet know the number of murine bone marrow cells which actually acquire the TAN-1 cDNA in the transplant experiments or the identity of the target cell that is susceptible to transformation. The frequency of leukemias in the transplanted mice is probably also affected to some degree by the stochastic acquisition of other mutations, which, in addition to transduction of altered $T A N-1$, are probably required for malignant transformation of $\mathrm{T}$ cells. However, the high overall incidence of leukemia in the transplanted mice and the relatively short latency period suggest that the number of additional genetic events required for transformation is small.

Given the potency of truncated TAN-1 in transforming $\mathrm{T}$ cells, the relative rarity of human leukemias with the $\mathrm{t}(7 ; 9)(\mathrm{q} 34 ; \mathrm{q} 34.3)$ may reflect a narrow interval during T-cell development during which the translocation can exert its oncogenic effect. Alternatively, some structural feature of DNA within the TAN-1 gene may make translocation in the critical region of the gene unlikely. These experiments also show that production of a chimeric gene product, for instance, between the $\beta$ T-cell receptor and tan- 1 , is not essential for transformation. In light of this fact, perhaps the proper positioning or activation of a promoter that can function in T cells is the most important feature of translocations which will transform $T$ cells through truncation of $T A N-1$.

The structure and subcellular localization of the polypeptides encoded by $T A N-1$ cDNAs that exhibit transforming activity are difficult to reconcile in several respects with the tan-1 polypeptides detected in cells either containing or lacking the $t(7 ; 9)(q 34 ; q 34.3)$. Analyses of the tan-1 polypeptides in cells with intact $T A N-1$ genes show extensive proteolytic cleavage of the fulllength protein, $\mathrm{p} 350$, within the extracellular part of the protein near the transmembrane domain. The proteolytic product containing the intracellular portion of tan-1, p120, closely resembles the major truncated tan-1 polypeptide found in the cell line SUP-T1, containing the $t(7 ; 9)(q 34 ; q 34.3)$. Furthermore, both of these polypeptides are similar to the transforming polypeptides expressed from the $\Delta \mathrm{ECT}+\mathrm{S}(\mathrm{L})$ and $\triangle \mathrm{ECT}+\mathrm{S}(\mathrm{L}) \mathrm{cDNAs}$. These observations suggest that p120 ought to be functionally similar to polypeptides encoded by transforming cDNAs. However, all evidence at present indicates that p120 has no transforming potential in T-lineage cells, even when generated presumably at high levels from viruses carrying a fulllength $T A N-1$ cDNA in additional murine bone marrow transplant experiments (W.S. Pear et al., unpubl.).

One obvious difference between the normal p120 and the truncated product in SUP-T1 is the subcellular location of the proteins. At least in transfected cells, p120 seems to be located predominantly in the cytoplasm, whereas truncated tan-1 in SUP-T1 is found primarily in the nucleus. These locations are consistent with the divergent mechanisms by which the proteins are produced. p120 is presumably derived from $\mathrm{p} 350$ after insertion into the membrane of the endoplasmic reticulum, but the truncated product in SUP-T1 may be inefficiently inserted into membranes due to the lack of a signal peptide. However, like p120, both the $\triangle E C T+$ $\mathrm{S}(\mathrm{L})$ and $\triangle \mathrm{ECT}+\mathrm{S}(\mathrm{L})$ polypeptides in transformed murine $\mathrm{T}$ cells accumulate preferentially in the cytoplasm, as expected on the basis of the structure of the encoded proteins. Therefore, neither the cytoplasmic location nor the membrane association appears to account for the inability of p120 to transform T cells, despite the resemblance of this polypeptide to oncogenic versions of tan-1. This paradox suggests that p120 may differ from transforming polypeptides in tertiary structure and/or in its ability to associate with unknown regulatory factors involved in tan-1 signaling.

The teleologic reason for the intense nuclear localization of the truncated tan-1 polypeptides in SUP-T1 is not clear. As discussed above, abundant intranuclear $\tan -1$ polypeptide does not seem to be required for transformation. Therefore, if transformation indicates some exaggerated physiological effect of tan-1, nuclear localization is not a prominent feature of tan-1 function. Moreover, no cross-reacting tan-1 polypeptide could be detected by immunofluorescence in the nuclei of transfected cells expressing large amounts of p350 and $\mathrm{p} 120$.

Nevertheless, the presence of some nuclear tan-1 polypeptide cannot be ruled out. It may be that small amounts of $\tan -1$ polypeptide do move to the nucleus and that very little protein within the nucleus is neces- 
sary for transformation. This scenario is reminiscent of the situation recently described for the sterol-regulatory element binding protein (SREBP-1) (Wang et al. 1994). The precursor form of this protein is inserted into the endoplasmic reticulum and nuclear envelope of cells, where it is proteolytically processed in response to low sterol levels. A fragment of the processed protein migrates to the nucleus and up-regulates expression of genes for enzymes involved in sterol synthesis. SREBP1 is very unstable within the nucleus, being undetectable in the absence of a specific inhibitor that blocks intranuclear degradation of the protein.

The analogy of tan-1 to SREBP-1 would be even more complete if tan-1 served some role in transcription activation, as suggested by our data on the ability of $\tan -1$ to activate transcription in yeast. The relevance of transcriptional activity detected in this heterologous system remains to be determined, although the magnitude of activity displayed by the $\tan -1$ sequences is unusual for a purely artifactual result. If $\tan -1$ possesses physiological intranuclear activity of any kind, such activity would depend on an additional cleavage of the full-length or previously processed protein at some position on the cytoplasmic side of the transmembrane domain in order to free the polypeptide from the membrane. To date, we have detected no evidence of such a cleavage. On the other hand, the presence of the highly efficient nuclear localization signals identified within the intracellular portion of the tan-1 protein would certainly be consistent with intranuclear function. The alternative explanation for these signals is that they are merely fortuitous.

Studies of notch in Drosophila suggest that this protein transmits developmental signals across the plasma membrane of cells in a number of tissues. This transduction is likely to involve the binding ligands on both the extra- and intracellular sides of the membrane. In humans, the nature of the extracellular ligand is completely unknown; however, our work has demonstrated that bcl-3 is a strong candidate for an intracellular ligand. The interaction between bcl- 3 and tan- 1 was revealed through a screen for possible ligands expressed by a library of human endothelial cell cDNAs. This library was utilized for this purpose solely because it was known to contain TAN-1 cDNAs as well as cDNAs for a wide variety of other genes. Despite the random and unbiased nature of this screen, the protein detected to bind to the intracellular portion of tan-1 is one associated with lymphocytes, having originally been discovered as the product of a gene lying at the breakpoint of a translocation, $t(14 ; 19)(q 32 ; q 13)$, found in the neoplastic B cells of certain cases of chronic lymphocytic leukemia (McKeithan et al. 1987, 1990).

The binding of bcl-3 to tan-1 has at least two important implications. First, interaction between bcl-3 and tan- 1 occurs through ankyrin repeats present in both proteins, a type of interaction that has not been described previously. Second, since bcl-3 has been shown to be a regulator of NF- $\kappa$ B (Franzoso et al. 1992; Kerr et al. 1992; Fujita et al. 1993; Nolan et al. 1993), interaction of $\tan -1$ with bcl- 3 suggests that $\tan -1$ may be involved indirectly in the transcriptional control of genes regulated by NF- $\kappa$ B. The role of $\tan -1$ within the NF- $\kappa \mathrm{B}$ pathway of gene regulation is not evident at this time. Perhaps, under certain circumstances, tan- 1 serves to sequester bcl-3 in a perinuclear location and thereby alters transcription of genes under NF- $\kappa$ B control. This model by no means eliminates the possibility of other actions by tan-1 in lymphoid or other tissues. However, involvement of tan-1 in the NF- $\kappa$ B pathway does highlight the expanding number of positions at which this pathway is vulnerable to genetic modifications which can contribute to malignant transformation. Along with $B C L-3$ and the rel family of oncogenes (Nolan and Baltimore 1992), including $L Y T-10$, another translocation-associated human oncogene (Neri et al. 1991), TAN-1 brings to three the number of genes with transforming potential related to the NF- $\kappa \mathrm{B}$ pathway. Very likely, additional genes producing products that impinge on NF- $\kappa \mathrm{B}$ will be found to have similar properties in the near future.

\section{REFERENCES}

Bierkamp, C. and J.A. Campos-Ortega. 1993. A zebrafish homologue of the Drosophila neurogenic gene Notch and its pattern of transcription during early embryogenesis. Mech. Dev. 43: 87.

Blackwood, E.M. and R.N. Eisenman. 1991. Max: A helixloop-helix zipper protein that forms a sequence-specific DNA-binding complex with Myc. Science 251: 1211.

Cleveland, D.W., S.G. Fischer, M.W. Kirschner, and U.K. Laemmli. 1977. Peptide mapping by limited proteolysis in sodium dodecyl sulfate and analysis by gel electrophoresis. J. Biol. Chem. 252: 1102 .

Coffman, C., W. Harris, and C. Kintner. 1990. Xotch, the Xenopus homologue of Drosophila Notch. Science 249: 1438.

Daley, G.Q., R. van Etten, and D. Baltimore. 1990. Induction of chronic myelogenous leukemia in mice by the $\mathrm{P} 210^{b c r / a b l}$ gene of the Philadelphia chromosome. Science 247: 824.

Dutta, A., J.M. Rupert, J.C. Aster, and E. Winchester. 1993. Inhibition of DNA replication factor RPA by $p 53$. Nature 365: 79

Ellisen, L.W., J. Bird, D.C. West, A.L. Soreng, T.C. Reynolds, S.D. Smith, and J. Sklar. 1991. TAN-I, the human homolog of the Drosophila Notch gene, is broken by chromosomal translocations in T lymphoblastic neoplasms. Cell 66: 649 .

Fortini, M.E. and S. Artavanis-Tsakonis. 1993. Notch: Neurogenesis is only part of the story. Cell 75: 1245 .

Franco del Amo, F., D.E. Smith, P.J. Swiatek, M. GendronMaguire, R.J. Greenspan, A.P. McMahon, and T. Gridley. 1992. Expression pattern of Motch, a mouse homolog of Drosophila Notch, suggests an important role in post-implantation development. Development 115: 737.

Franzoso, G., V. Bours, S. Park, M. Tomita-Yamaguchi, K Kelly, and U. Siebenlist. 1992. The candidate oncoprotein $\mathrm{Bcl}-3$ is an antagonist of $\mathrm{p} 50 / \mathrm{NF}-\kappa \mathrm{B}$-mediated inhibition. Nature 359: 339

Fujita, T., G. Nolan, H. Liou, M. Scott, and D. Baltimore. 1993. The candidate proto-oncogene $b c l-3$ encodes a transcriptional coactivator that activates through NF- $\kappa$ B p50 homodimers. Genes Dev. 7: 1354

Ghysen, A., C. Dambly-Chaudiere, L.Y. Jan, and Y.N. Jan. 1993. Cell interactions and gene interactions in peripheral neurogenesis. Genes Dev. 7: 723 .

Ginsburg, D., R.I. Handin, D.T. Bonthron, T.A. Donlon, G.A. 
Bruns, S.A. Latt, and S.H. Orkin. 1985. Human von Willebrand factor (vWF): Isolation of complementary DNA (cDNA) clones and chromosomal localization. Science 228: 1401 .

Harlow, E. and D. Lane. 1988. Antibodies: A laboratory manual. Cold Spring Harbor Laboratory, Cold Spring Harbor, New York.

Kaelin, J., W.G., W. Krek, W.R. Sellers, J.A. DeCaprio, F. Ajchenbaum, C.S. Fuchs, T. Chittenden, Y. Li, P.J. Farnham, M.A. Blanar, D.M. Livingston, and E.K. Flemington. 1992. Expression cloning of a cDNA encoding a retinoblastoma-binding protein with E2F-like properties. Cell 70: 351

Kerr, L.D., C.S. Duckett, P. Wamsley, A. Zhan, P. Chiao, G. Nabel, T.W. McKeithan, P.A. Baeuerle, and I.M. Verma. 1992 . The proto-oncogene $B C L-3$ encodes an $\mathrm{I} \kappa \mathrm{B}$ protein. Genes Dev. 6: 2352.

Laemmli, U.K. 1970. Cleavage of structural proteins during the assembly of the head of bacteriophage T4. Nature 227: 680 .

Lardelli, M. and U. Lendahl. 1993. MotchA and MotchB: Two mouse Notch homologs co-expressed in a wide variety of tissues. Exp. Cell Res. 204: 364.

Lux, S.E., K.M. John, and V. Bennett. 1990. Analysis of cDNA for human erythrocyte ankyrin indicates a repeated structure with homology to tissue-differentiation and cell-cycle control proteins. Nature 334: 36.

McKeithan, T.W., H. Ohno, and M.O. Diaz. 1990. A transcriptional unit lies adjacent to the breakpoint on chromosome 19 in the $t(14 ; 19)$ in chronic lymphocytic leukemia. Genes Chromosomes Cancer 1: 247.

McKeithan, T.W., J.D. Rowley, T.B. Shows, and M.O. Diaz. 1987. Cloning of the chromosome translocation breakpoin junction of the $\mathrm{t}(14 ; 19)$ in chronic lymphocytic leukemia. Proc. Natl. Acad. Sci. 84: 9257.

Neri, A., C.-C. Chang, L. Lombardi, M. Salina, P. Corradini, A.T. Maiolo, R.S.K. Chaganti, and R. Dalla-Favera. 1991 $B$ cell lymphoma-associated chromosomal translocation involves candidate oncogene $l y t-10$, homologous to NF- $\kappa \mathrm{B}$ p50. Cell 67: 1075.

Nolan, G.P. and D. Baltimore. 1992. The inhibitory ankyrin and activator Rel proteins. Curr. Opin. Genet. Dev. 2: 211

Nolan, G., T. Fujita, K. Bhatia, C. Huppi, H. Liou, M. Scott, and D. Baltimore. 1993. The $b c l-3$ proto-oncogene encodes a nuclear $\mathrm{I} \kappa \mathrm{B}$-like molecule that preferentially interacts with NF- $\kappa$ B p50 and p52 in a phosphorylation-dependent manner. Mol. Cell. Biol. 13: 3557.

Pear, W.S., G.P. Nolan, M.L. Scott, and D. Baltimore. 1993
Production of high-titer helper-free retroviruses by transient transfection. Proc. Natl. Acad. Sci. 90: 8392.

Pinkus, G.S., E.M. O'Connor, C.L. Etheridge, and J.M. Corson. 1985. Optimal immunoreactivity of keratin proteins in formalin-fixed paraffin-embedded tissues requires the use of preliminary trypsinization. An immunoperoxidase study of various tumours using polyclonal and monoclonal antibodies. J. Histochem. Cytochem. 33: 465 .

Reaume, A.G., R.A. Conlon, R. Zirngibl, T.P. Yamaguchi, and J. Rossant. 1992. Expression analysis of a Notch homologue in the mouse embryo. Dev. Biol. 154: 377.

Rebay, I., R.J. Fleming, R.G. Fehon, L. Cherbas, P. Cherbas, and S. Artavanis-Tsakonas. 1991. Specific EGF repeats of Notch mediate interactions with delta and serrate: Implications for Notch as a multifunctional receptor. Cell 67: 687 .

Reynolds, T.C., S.D. Smith, and J. Sklar. 1987. Analysis of DNA surrounding the breakpoints of chromosomal translocations involving the $\beta$ T cell receptor gene in human lymphoblastic neoplasms. Cell 50: 107.

Robbins, J., B.J. Blondel, D. Gallahan, and R. Callahan. 1992 Mouse mammary tumor gene int-3: A member of the notch gene family transforms mammary epithelial cells. J. Virol. 66: 2594

Smith, S.D., R. Morgan, R. Gemmill, M.D. Amylon, M.P Lind, C. Linker, B.K. Hecht, R. Warnke, B.E. Glader, and R. Hecht. 1988. Clinical and biological characterization of $\mathrm{T}$ cell neoplasias with rearrangements of chromosome 7 band q34. Blood 71:395.

Stifani, S., C.M. Blaumueller, N.J. Redhead, R.E. Hill, and S Artavanis-Tsakonas. 1992. Human homologs of a Drosophila Enhancer of Split gene product define a novel family of nuclear proteins. Nat. Genet. 2: 119.

Towbin, H., T. Staehelin, and J. Gordon. 1979. Electrophoretic transfer of proteins from polyacrylamide gels to nitrocellulose sheets: Procedure and some applications. Proc. Natl. Acad. Sci. 76: 4350.

Wang, X., R. Sato, M.S. Brown, X. Hua, and J.L. Goldstein. 1994. SREBP-1, a membrane-bound transcription factor released by sterol regulated proteolysis. Cell 77: 53 .

Weinmaster, G., V.J. Roberts, and G. Lemke. 1991. A homolog of Drosophila Notch expressed during mammalian development. Development 113: 199.

1992. Notch2: A second mammalian Notch gene. Development 116: 931.

Zervos, A.S., J. Gyuris, and R. Brent. 1993. Msi1, a protein that specifically interacts with Max to bind Myc-Max recognition sites. Cell 72: 223 . 